\title{
Cationic Homo- and Co-polymerizations of Ethyl Glycidate
}

\author{
Takeo SAEguSA, ${ }^{*}$ Takatoshi KobayASHI, ${ }^{*}$ Shiro KobAYASHI, ${ }^{*}$ \\ Signe L-COUCHMAN, ${ }^{* *}$ and Otto VOGL ${ }^{* *}$ \\ *Department of Synthetic Chemistry, Faculty of Engineering, \\ Kyoto University, Kyoto 606, Japan. \\ ** Polymer Science and Engineering Department, University of Massachusetts, \\ Amherst, MA 01003, U.S.A.
}

(Received September 16, 1978)

\begin{abstract}
Cationic homo- and co-polymerizations of ethyl glycidate (EG) have been studied with triethyloxonium tetrafluoroborate (TEOFB) and superacid ester catalysts. The homopolymerization of EG gave a paste-like material of low molecular weight with TEOFB catalyst. A superacid ester catalyst such as ethyl trifluoromethanesulfonate underwent only the initiation process with EG and the propagation was negligibly slow in this system. Copolymerization of EG with tetrahydrofuran (THF) gave a copolymer with TEOFB. When THF remained unreacted after the completion of copolymerization, the copolymer composition was in all cases EG :THF $=1: 2$. These results were understood in terms of the penultimate effect. The same copolymerization by a superacid ester catalyst, however, always yielded copolymers of the EG/THF $=1 / 2$ composition. This result was explained in the same way as the TEOFB case, taking the EG polymerizability by a superacid ester into account.
\end{abstract} KEY WORDS Ethyl Glycidate / Cationic Polymerization /
Copolymerization / Tetrahydrofuran / Oxonium Salt / Superacid Ester /
Penultimate Effect /

Cyclic ethers and particularly epoxides have been known for a long time to polymerize to polyethers even of very high molecular weight. ${ }^{1,2}$ While cyclic ethers polymerize primarily with classical cationic initiators and aluminum and zinc organic compounds by what is often referred to as coordinative anionic polymerization, ${ }^{3}$ epoxides undergo polymerization by classical cationic and anionic mechanisms and also by the above mentioned coordinative mechanism. ${ }^{1,2}$ Most of the work has been done on unsubstituted and methyl-substituted compounds, namely ethylene oxide and propylene oxide; substitutent groups with higher polarity and the functionality have not been studied to any extent. The monomers with the most reactive groups were those with a chloromethyl substitution as, for example, in epichlorohydrin ${ }^{4}$ and 3,3-bis(chloromethyl)oxetane. ${ }^{5}$

Epoxides which have functional groups directly attached to the epoxide rings have been already known. ${ }^{6}$ Their synthesis is not particularly easy as it requires trifluoroperacetic acid as the oxidizing agent, which in turn must be prepared from $90 \%$ $\mathrm{H}_{2} \mathrm{O}_{2}$ and trifluoroacetic acid. Glycidaldehyde, ${ }^{7}$ glycidyl esters, ${ }^{8}$ and glycidonitrile ${ }^{7}$ have been prepared; glycidaldehyde was polymerized via both the epoxide group and the aldehyde group, depending on the reaction conditions. ${ }^{9}$ These monomers have been copolymerized with trioxane ${ }^{10}$ and the properties of co- and ter-polymers with 1,3-dioxolane with a relatively low percentage of glycidate incorporated were investigated. ${ }^{11}$ These polymers were then hydrolyzed to the corresponding poly(oxymethylene)ionomers and their free acids. The co- and terpolymerizations were accomplished with classical cationic initiators, both in bulk solution ${ }^{11}$ and by a process in which the monomers were mixed in the vapor phase. ${ }^{12}$

It was the purpose of this work to study the cationic homo-'and co-polymerization of ethyl glycidate, especially the investigation of suitable initiators and conditions for the production of highmolecular-weight homopolymer and copolymer. 


\section{EXPERIMENTAL}

\section{Materials}

EG was synthesized by epoxidation of ethyl acrylate with a mixture of trifluoroacetic anhydride and $90 \% \mathrm{H}_{2} \mathrm{O}_{2} \cdot{ }^{13,14} \mathrm{~A}$ yield of less than $50 \%$ was normally obtained. The other major side product was ethyl $\beta$-trifluoroacetoxy- $\alpha$-hydroxypropionate: this product can be cyclized with $\mathrm{NaH}$ to the epoxide.

Tetrahydrofuran (THF) and $\mathrm{CH}_{2} \mathrm{Cl}_{2}$ were purified as previously reported. ${ }^{15}$

Triethyloxonium tetrafluoroborate (TEOFB) was synthesized according to Meerwein's method. ${ }^{16}$ Ethyl (EtOTf) and methyl trifluoromethanesulfonate (MeOTf) were synthesized according to a previously published procedure. ${ }^{17,18}$

\section{Measurements}

NMR Measurements. $\quad{ }^{1} \mathrm{H}$ NMR spectra were taken on a Varian HA-100 or Hitachi R-20B $(60 \mathrm{MHz})$ instrument. ${ }^{19} \mathrm{~F}$ NMR spectra were taken on a Hitachi R-20B (54 MHz) instrument.

Molecular Weight Determinations. The molecular weights of all polymers were measured by vapor pressure osmometry (Hitachi Perkin-Elmer Model 115) in $\mathrm{CHCl}_{3}$ at $35^{\circ} \mathrm{C}$.

The infrared spectra were recorded on a Hitachi Grating Infrared Spectrophotometer, Model EPIG3.

Column chromatography to fractionate a sample of EG-THF copolymer was carried out on a silica gel column and $\mathrm{CHCl}_{3}$ was used as the carrier solvent.

\section{Preparations}

Polymerization Procedures. All polymerizations were carried out under dry nitrogen. A carefully dried NMR tube $(5 \mathrm{~mm} \times 150 \mathrm{~mm})$ was closed with a three-way cock and placed into a dry ice-ethanol bath at $-78^{\circ} \mathrm{C}$. Solvent and initiator or initiator solutions were introduced into this tube with a microsyringe. The NMR tube was then sealed and shaken to prevent the contents from warming above the bath temperature. The tube was then gradually warmed to room temperature and was kept at $35^{\circ} \mathrm{C}$ to allow the polymerization to proceed. When desirable, the reaction was followed by monitoring the ${ }^{1} \mathrm{H}$ or ${ }^{19} \mathrm{~F}$ NMR spectrum at $35^{\circ} \mathrm{C}$. After the reaction was considered complete, the polymerization was stopped by opening the NMR tube and adding an approximately $10 \%$ solution of aqueous ammonia in methanol $(0.1 \mathrm{~m} l)$. The mixture was then poured into a large excess of hexane $(30-50 \mathrm{~m} l)$. The polymer precipitated under these conditions; it was isolated by decantation and dried in vacuo at $0.1 \mathrm{~mm}$. If a soluble fraction was obtained, the mother liquid was evaporated to dryness under reduced pressure and the residue was identified.

Hydrolysis of EG-THF Copolymer. In a $50 \mathrm{ml}$ Erlenmeyer flask, a copolymer of EG-THF $1: 2$ $(0.273 \mathrm{~g})$ was added to $7.0 \mathrm{~m} l$ of aqueous $0.2 \mathrm{~N}$ $\mathrm{NaOH}$ solution. The initially heterogeous mixture was heated to $80^{\circ} \mathrm{C}$ under nitrogen, and the reaction allowed to proceed for $10 \mathrm{~h}$, by which time it became homogeneous. The mixture was then cooled to room temperature and divided into two parts. From one part of the mixture $(3 \mathrm{~m} l)$ the water was evaporated and the polymer extracted with chloroform. The chloroform solution was dried over sodium sulfate and evaporated under reduced pressure; it gave $0.103 \mathrm{~g}$ of the sodium salt of the copolymer.

To the other part of the aqueous solution $(4.0 \mathrm{~m} l)$ was added $0.2 \mathrm{~N} \mathrm{HCl}(2.5 \mathrm{~m} l)$; the water was evaporated and the polymer was extracted with chloroform. After the evaporation, $0.126 \mathrm{~g}$ of the free acid of the copolymer was obtained.

\section{RESULTS AND DISCUSSION}

Homopolymerization of EG and its copolymerization, primarily with THF and also with other cyclic ethers, to very low-molecular-weight polymers have been accomplished with oxonium salts and superacid esters. It was not suprising that triflic acid derivatives gave polymers of low molecular weight, in view of our earlier experience in the preparation of poly(ethylene oxide) from ethylene oxide. ${ }^{19}$ The other possible source of low molecular weight of our Poly-EG and copolymers is the cationic chain transfer possibility of the ester group, as described below.

\section{Homopolymerization of $E G$}

Triethyloxonium Tetrafluoroborate (TEOFB) as the Initiator. EG was polymerized with TEOFB at $35^{\circ} \mathrm{C}$ in $\mathrm{CH}_{2} \mathrm{Cl}_{2}$. The monomer (EG) was completely consumed under these conditions and a polymer was obtained as a paste-like material, which was soluble in methanol, diethyl ether, acetone, $\mathrm{CHCl}_{3}$, and $\mathrm{CH}_{2} \mathrm{Cl}_{2}$, but was only partially soluble in hexane. 


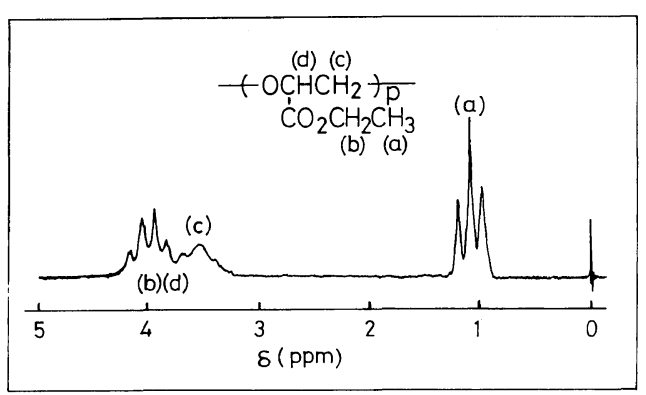

Figure 1. $100 \mathrm{MHz}{ }^{1} \mathrm{H}$ NMR spectrum of Poly-EG in $\mathrm{CDCl}_{3}$ (chemical shift in $\delta$ (ppm) relative to TMS).

The molecular weight of the polymer was found to be low. The hexane soluble fraction was $68 \%$ in weight of the total polymer; the molecular weight of this fraction was 460 . The hexane-insoluble part consisted of $32 \%$ of the total polymer; its molecular weight was 1200 as measured by VPO. The structure of the polymer is consistent with a carboxy substituted poly(ethylene oxide) (eq 1) of structure 1, whose ${ }^{1} \mathrm{H}$ NMR spectrum is shown in Figure 1. A triplet at $1.1 \mathrm{ppm}$ indicates the methyl group and a quartet at $4.1 \mathrm{ppm}$ the methylene group of the ethyl ester group. Broad overlapping bands between 3.5 and $4 \mathrm{ppm}$ indicate the methylene and methine protons.

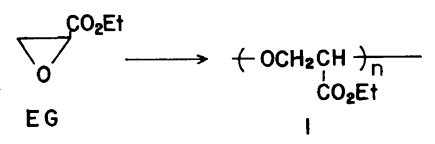

Superacid Esters as Initiators. At $35^{\circ} \mathrm{C}$ the polymerization of EG with methyl (MeOTf) and ethyl trifluoromethanesulfonate (EtOTf) proceeded very slowly; however, at $60^{\circ} \mathrm{C}$ a polymer of EG was obtained in a $28 \%$ yield after 5 days. $70 \%$ of EG was converted to an hexane-insoluble polymer when $[\mathrm{EG}]_{0}=4.8 \mathrm{~mol} / l$ and $[\mathrm{MeOTf}]_{0}=4.7 \mathrm{~mol} \%$ for [EG] $]_{0}$ were used in $\mathrm{CH}_{2} \mathrm{Cl}_{2}$.

The initiation step was examined by ${ }^{19} \mathrm{~F}$ NMR spectroscopy. A mixture of $5.0 \mathrm{mmol}$ of EG and 5.2 mmol EtOTf in $5 \mathrm{~m} l$ of chloroform was kept at $35^{\circ} \mathrm{C}$ for 30 days. A ${ }^{19} \mathrm{~F}$ NMR spectrum developed and showed three peaks at $-3.17,-2.88$, and -2.73 ppm (relative to $\mathrm{CF}_{3} \mathrm{CO}_{2} \mathrm{H}$ ) in a relative intensity ratio of 22,10 , and $68 \%$, respectively. The resonance peak at $-2.73 \mathrm{ppm}$ was identified as unreacted EtOTf. It was found that $58 \%$ of the EG was consumed. The course of the reaction was confirmed by ${ }^{1} \mathrm{H}$ NMR spectroscopy, which indicated that the main reaction consisted of an addition of EtOTf to EG and gave a 1:1-reaction product.

The main course of the reaction can be described by the following scheme.

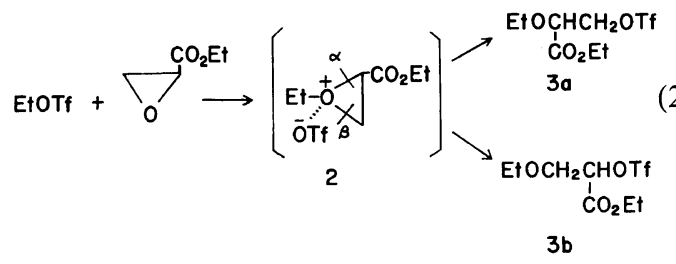

The intermediate oxonium ion, $\mathbf{2}$, is unstable and evidently undergoes immediate further reaction because it was not detected. Two peaks $(-3.17 \mathrm{ppm}$ and $-2.88 \mathbf{p p m})$ are the triflic esters $\mathbf{3 a}$ and $\mathbf{3 b}, \mathbf{3 a}$ being the $\beta$-scission product of 2 and $3 \mathrm{~b}$ being the $\alpha$ scission product of 2 . Other peak assignments, however, have not been established yet. Both $\alpha$ and $\beta$-scissions of the growing oxonium ion or oxonium end are probably involved also in the propagating stage. We have not made any attempts at this time to distinguish between $\alpha$ and $\beta$-scissions in the propagating step in further cationic polymerization work, as the NMR spectra are still too complicated to be fully analyzed. For simplicity, only the $\beta$ scission mode is indicated in this paper, although it should be emphasized that $\alpha$ and $\beta$-scissions are in principle possible in this polymerization, leading to $\mathrm{H}-\mathrm{H}$ and $\mathrm{H}-\mathrm{T}$ linkages.

When MeOTf was used as the initiator for the polymerization of EG, EtOTf was produced, in addition to oligomers which have both ethyl or methyl ester groups in the ester group. The formation of these species obviously occurred because of the very efficient ester exchange reaction indicated in eq 3 . This exchange reaction between carboxylic esters and fluorosulfonate esters is not unknown and has been specifically noted in the reaction between methyl acetate and ethyl fluorosulfonate. ${ }^{18}$

\section{Copolymerization of EG with THF}

Triethyloxonium Tetrafluoroborate as Initiator. The copolymerization of EG with THF was carried out with various monomer concentrations at $35^{\circ} \mathrm{C}$ in $\mathrm{CH}_{2} \mathrm{Cl}_{2}$. The THF concentration used was

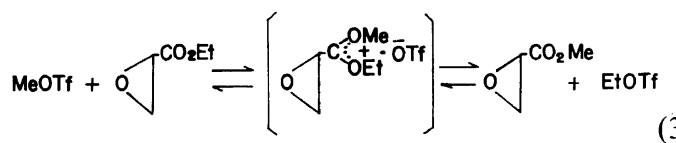


T. Saegusa, T Kobayashi, S. Kobayashi, S. L-Couchman, and O. Vogl

Table Ia. Reaction conditions of the cationic copolymerization of $\operatorname{EG}\left(\mathrm{M}_{1}\right)-\operatorname{THF}\left(\mathrm{M}_{2}\right)$ with triethyloxonium tetrafluoroborate as initiator ${ }^{\mathbf{a}}$

\begin{tabular}{|c|c|c|c|c|c|}
\hline \multirow{2}{*}{$\begin{array}{l}\text { Sample } \\
\text { no. }\end{array}$} & \multicolumn{3}{|c|}{ Initial monomer concentration } & \multirow{2}{*}{$\begin{array}{c}\text { Reaction } \\
\text { time, } \\
h\end{array}$} & \multirow{2}{*}{$\begin{array}{l}{\left[\mathrm{M}_{2}\right]_{\mathrm{e}},} \\
\mathrm{mol} / \mathrm{l}\end{array}$} \\
\hline & $\begin{array}{l}{\left[\mathrm{M}_{1}\right]_{0}} \\
\mathrm{~mol} / l\end{array}$ & $\begin{array}{l}{\left[\mathrm{M}_{2}\right]_{0}} \\
\mathrm{~mol} / l\end{array}$ & $\begin{array}{c}{\left[\mathbf{M}_{1}\right]_{0} /\left(\left[\mathrm{M}_{1}\right]_{0}+\left[\mathrm{M}_{2}\right]_{0}\right)} \\
\mathrm{mol}^{\mathrm{o}} \%\end{array}$ & & \\
\hline 1 & 3.82 & 0.99 & 79.5 & 12 & 0 \\
\hline 2 & 2.28 & 1.18 & 66.0 & 6 & 0 \\
\hline 3 & 3.63 & 3.66 & 49.8 & 8 & 0 \\
\hline 4 & 1.37 & 2.65 & 34.1 & 14 & 0 \\
\hline 5 & 1.10 & 2.95 & 27.1 & 11 & 0.68 \\
\hline 6 & 0.96 & 3.70 & 20.5 & 12 & 1.42 \\
\hline 7 & 0.48 & 3.70 & 11.5 & 12 & 1.92 \\
\hline 8 & 0.16 & 3.24 & 4.8 & 12 & 2.98 \\
\hline
\end{tabular}

${ }^{\mathrm{a}}[\mathrm{I}]_{0}=1.8 \%$; solvent, $\mathrm{CH}_{2} \mathrm{Cl}_{2}$; reaction temp, $35^{\circ} \mathrm{C}$.

Table Ib. Cationic copolymerization of $\operatorname{EG}\left(\mathbf{M}_{1}\right)-\operatorname{THF}\left(\mathbf{M}_{2}\right)$ with triethyloxonium tetrafluoroborate as initiator; copolymer compositions

\begin{tabular}{|c|c|c|c|c|c|c|}
\hline \multirow{2}{*}{$\begin{array}{l}\text { Sample } \\
\text { no. }\end{array}$} & \multicolumn{3}{|c|}{ Insoluble part in hexane } & \multicolumn{3}{|c|}{ Soluble part in hexane } \\
\hline & $\begin{array}{c}\text { Yield, }{ }^{a} \\
\%\end{array}$ & $\begin{array}{c}\mathrm{M}_{1} /\left(\mathrm{M}_{1}+\mathrm{M}_{2}\right){ }^{\mathrm{b}} \\
\%\end{array}$ & $M_{w}$ & $\begin{array}{l}\text { Yield, } \\
\%\end{array}$ & $\begin{array}{c}\mathbf{M}_{1} /\left(\mathbf{M}_{1}+\mathbf{M}_{2}\right){ }^{\mathrm{b}} \\
\%\end{array}$ & $M_{w}$ \\
\hline 1 & 92.3 & 79.1 & 1180 & 5.4 & 81.8 & 410 \\
\hline 2 & 81.6 & 66.4 & 1630 & 10.8 & 65.2 & 520 \\
\hline 3 & 73.8 & 50.8 & 3860 & 15.6 & 50.5 & 320 \\
\hline 4 & 80.6 & 35.2 & 3630 & 4.8 & 35.5 & - \\
\hline 5 & 71.4 & 34.8 & 1480 & 5.5 & 33.2 & 360 \\
\hline 6 & 60.3 & 33.3 & 1280 & 9.4 & 36.8 & 420 \\
\hline 7 & 29.8 & 33.0 & 1220 & 5.2 & 32.5 & 390 \\
\hline 8 & 10.6 & 32.8 & 1160 & 2.3 & 34.3 & - \\
\hline
\end{tabular}

a Based on the total amount of the initial feed of monomers.

b Determined by ${ }^{1} \mathrm{H}$ NMR spectroscopy.

lower than the equilibrium monomer concentration of THF homopolymerization (which is $[\mathrm{M}]_{\mathrm{e}}=4.2$ $\mathrm{mol} / l$ at $35^{\circ} \mathrm{C}$ in $\mathrm{CH}_{2} \mathrm{Cl}_{2}$ ) (Table I). EG was consumed completely in all experiments. However, there was an equilibrium monomer concentration of THF which depended on the reaction conditions. It is clear however that the equilibrium monomer concentration of homopolymerization cannot normally be transferred to any copolymerizations, as it is quite possible to add two monomer units without infringing on the principle of equilibrium monomer concentration. This term should be understood here as the concentration of monomer which is not consumed anymore during copolymerization. The copolymer of EG and THF was paste-like, soluble in
Table II. Fractionation of oxonium salt initiated EG $\left(M_{1}\right)$-THF $\left(M_{2}\right)$ copolymer by column chromatography ${ }^{\mathrm{a}}$

\begin{tabular}{ccc}
\hline Fraction & $\begin{array}{c}\text { Weight, } \\
\mathrm{g}\end{array}$ & $\begin{array}{c}\text { Copolymer composition, } \\
\mathbf{M}_{1} /\left(\mathbf{M}_{1}+\mathbf{M}_{2}\right)^{\mathrm{b}} \mathrm{mol} \%\end{array}$ \\
\hline 1 & 0.140 & 34.2 \\
2 & 0.082 & 32.8 \\
3 & 0.072 & 33.6 \\
4 & 0.093 & 33.4 \\
\hline
\end{tabular}

a Copolymer sample no. 6 was used. Silica gel column was employed using $\mathrm{CHCl}_{3}$ as carrier solvent.

b The composition was determined by ${ }^{1} \mathrm{H}$ NMR spectroscopy. 
Table III. Cationic copolymerization of $\operatorname{EG}\left(\mathrm{M}_{1}\right)-\mathrm{THF}\left(\mathrm{M}_{2}\right)$ with ethyl triflate initiator in $\mathrm{CH}_{2} \mathrm{Cl}_{2}$ at $35^{\circ} \mathrm{C}$

\begin{tabular}{|c|c|c|c|c|c|c|c|c|c|}
\hline \multirow{2}{*}{$\begin{array}{l}\text { Sample } \\
\text { no. }\end{array}$} & \multicolumn{4}{|c|}{ Initial monomer concentration } & \multirow[b]{2}{*}{$\underset{\mathrm{h}}{\text { Time, }}$} & \multirow[b]{2}{*}{$\begin{array}{l}{\left[\mathrm{M}_{2}\right]_{\mathrm{e}}} \\
\mathrm{mol} / l\end{array}$} & \multicolumn{3}{|c|}{ Copolymer } \\
\hline & $\begin{array}{l}{\left[\mathrm{M}_{1}\right]_{0}} \\
\mathrm{~mol} / l\end{array}$ & $\begin{array}{l}{\left[\mathrm{M}_{2}\right]_{0}} \\
\mathrm{~mol} / l\end{array}$ & $\left.\underset{\%}{\left[\mathbf{M}_{1}\right]_{0} /\left(\left[\mathbf{M}_{1}\right]_{0}\right.}+\left[\mathbf{M}_{2}\right]_{0}\right)$ & $\begin{array}{l}{[\mathrm{I}]_{0}} \\
\mathrm{~mol} \%\end{array}$ & & & $\begin{array}{l}\text { Yield, } \\
\%\end{array}$ & $\begin{array}{c}\mathbf{M}_{1} /\left(\mathrm{M}_{1}+\mathrm{M}_{2}\right) \\
\%\end{array}$ & $M_{w}$ \\
\hline 9 & 0.43 & 3.31 & 11.4 & 12.5 & 72 & 2.42 & 33.3 & 32.3 & 1050 \\
\hline 10 & 0.58 & 2.78 & 17.3 & 12.0 & 15 & 1.72 & 48.1 & 35.0 & 1630 \\
\hline 11 & 0.79 & 2.50 & 24.0 & 10.0 & 50 & 0.95 & 69.1 & 33.4 & 1280 \\
\hline 12 & 2.58 & 2.66 & 49.7 & 7.5 & 25 & 0 & 74.6 & 33.5 & 1240 \\
\hline 13 & 2.70 & 1.40 & 65.9 & 8.5 & 26 & 0 & 57.2 & 34.5 & 1060 \\
\hline
\end{tabular}

${ }^{a}$ Based on the total amount of initial feed.

b Determined by ${ }^{1} \mathrm{H}$ NMR spectroscopy.

acetone, methanol, diethyl ether, $\mathrm{CHCl}_{3}, \mathrm{CH}_{2} \mathrm{Cl}_{2}$, and $\mathrm{CH}_{3} \mathrm{CN}$, and partially soluble in hexane. The copolymer composition was essentially the same in the hexane-insoluble and hexane-soluble portions of the polymer (Table I).

In order to demonstrate that a true copolymer was obtained with a reasonably constant copolymer composition, a copolymer sample was fractionated by column chromatography (Table II). The copolymer composition in four fractions was within a narrow range, which indicates that an actual copolymer of EG and THF was obtained. Figure 2 shows the relationship between the initial amount of monomer-feed ratio and the final polymer composition and Figure 3 illustrates the ${ }^{1} \mathrm{H}$ NMR spectrum of the copolymer (EG: $\mathrm{THF}=1: 2$ composition).

It should be noted that copolymers obtained in the systems above the equilibrium monomer concentration of THF $\left(\left[\mathrm{M}_{2}\right]_{\mathrm{e}}>0\right)$ showed in all cases a copolymer composition of $\mathrm{M}_{1}: \mathrm{M}_{2}=1: 2$ (see Table I). These results may be explained by considering the penultimate effect in this polymerization as follows. The nucleophilic reactivity of THF is much higher than that of EG, and hence, THF attacks preferentially the propagating oxonium ion of EG. The EG homounit formation is not possible because of the low nucleophilicity of the ring oxygen atom of EG and the propagating end of $\mathbf{4}$ is produced. THF attacks 4 exclusively because, again, of the higher nucleophilic reactivity of THF and produces $\mathbf{5}$, which does not depolymerize to give $\mathbf{4}$ due to the penultimate effect of the EG unit, probably reflected in the steric factor of EG. In the next addition step there is no more effect of the EG unit in $\mathbf{5}$ and the propagation of THF from 5 does not take place,

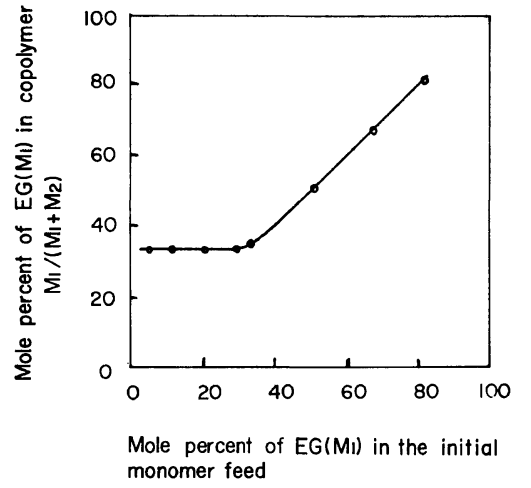

Figure 2. Curve of copolymer composition of $\operatorname{EG}\left(M_{1}\right)-\operatorname{THF}\left(M_{2}\right)$ mixtures initiated with triethyloxonium tetrafluoroborate in $\mathrm{CH}_{2} \mathrm{Cl}_{2}$ at $35^{\circ} \mathrm{C}$.

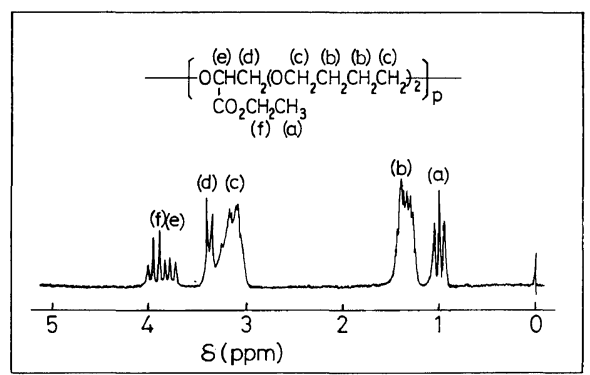

Figure 3. $100 \mathrm{MHz}{ }^{1} \mathrm{H}$ NMR spectrum of EG-THF copolymer in $\mathrm{CDCl}_{3}$ (chemical shift in $\delta(\mathrm{ppm})$ relative to TMS).

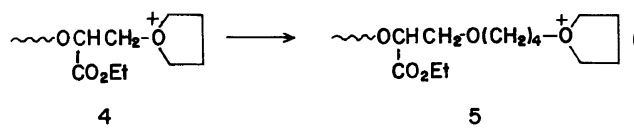


because the monomer concentration of THF is lower than that of the equilibrium concentration. Further addition of THF would require a higher concentration than the equilibrium one of THF homopolymerization. The same type of penultimate effect has been observed in the copolymerization of THF with 3,3-bis(chloromethyl)oxetane. ${ }^{20}$

The EG-THF polymer was hydrolyzed with $0.2 \mathrm{~N}$ $\mathrm{NaOH}$ and the sodium salt of the polyether ionomer was isolated. The infrared spectrum of the ionomer is shown in Figure 4, which also shows the infrared spectrum of the starting copolymer and that of the free acid which was obtained by neutralization of the salt. As expected, the characteristic features of the infrared spectra were the changes of the absorption band of $v_{\mathrm{C}=0}$. The $v_{\mathrm{C}=\mathrm{O}}$ of the ester is located at 1750 $\mathrm{cm}^{-1}$ (Figure 4a). The absorption band is shifted to $1610 \mathrm{~cm}^{-1}$ in the carboxylate form (Figure $4 \mathrm{~b}$ ) and the absorption band appears at $1710 \mathrm{~cm}^{-1}$ in the form of the free acid (Figure 4c). The copolymer

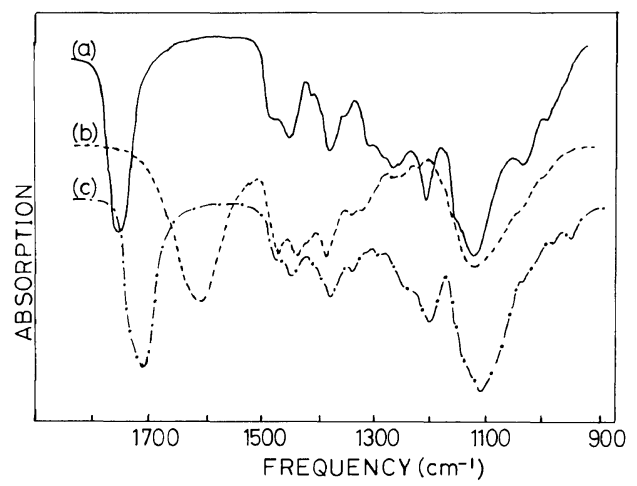

Figure 4. IR spectra of glycidate-THF copolymers: (a) EG-THF copolymer; (b) sodium glycidate-THF copolymer; (c) glycidic acid-THF copolymer.

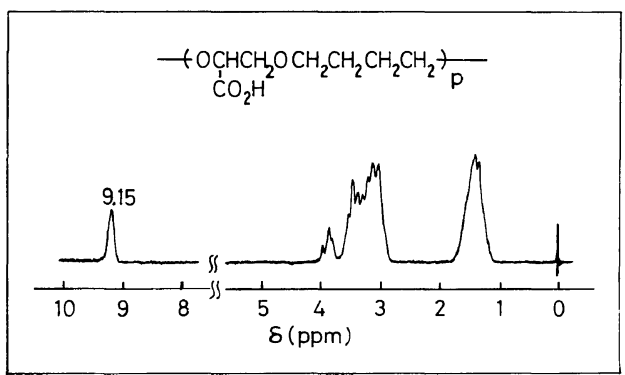

Figure 5. $60 \mathrm{MHz}{ }^{1} \mathrm{H}$ NMR spectrum of hydrolyzed copolymer in $\mathrm{CDCl}_{3}$ (chemical shift in $\delta(\mathrm{ppm})$ relative to TMS). structure of $\mathbf{6}$ is indicated by the infrared spectrum (4c) and also by the NMR spectrum which is free of the proton resonance of the ethyl group of the carboxylate (Figure 5) (eq 5).

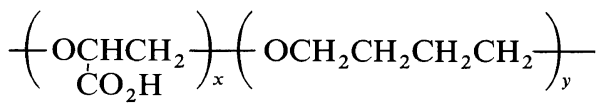

6

Superacid Ester as Initiator. Copolymerization of EG and THF with triflate esters proceeded slowly. It is interesting to note that the composition of the $\mathrm{EG} / \mathrm{THF}$ polymer is always in the ratio of $\mathrm{EG} / \mathrm{THF}=1 / 2$, regardless of the initial monomerfeed ratio (Table III). When the feed ratio was $\left[\mathrm{M}_{2}\right]_{0}>2\left[\mathrm{M}_{1}\right]_{0}$, the equilibrium monomer concentration of THF was observed as in the case of the TEOFB initiator. The reason why a $1: 2$-copolymer composition is obtained also in this case seems to be the same as in the case of the oxonium initiator system. When $\left[M_{1}\right]_{0}$ was higher than or approximately the same as $\left[\mathrm{M}_{2}\right]_{0}$, THF was consumed completely by copolymerization, showing a $\left[\mathrm{M}_{2}\right]_{\mathrm{e}}=0$, but the EG monomer remained still unreacted. This result is understandable because the homopolymerization of EG is a very slow reaction with EtOTf as the initiator. The mechanism of the EG/THF copolymerization is suggested as follows and involves the oxonium/macroester equilibrium, at least at the THF propagation end, a mechanism which has been described in detail previously. ${ }^{15,21}$ The EG species of the propagating ester 7 is attacked exclusively by THF because of the higher nucleophilic reactivity of THF and gives $\mathbf{8}$ which is in equilibrium with the ester species 9 . THF is again
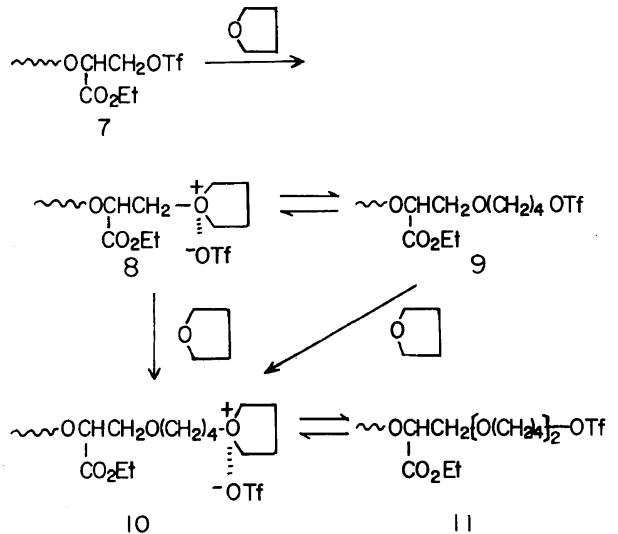
more reactive toward 8 and 9 and produces 10 and 11. Under the reaction conditions when $[\mathrm{THF}]$ is lower than $[\mathrm{M}]_{\mathrm{e}}, \mathbf{1 0}$ and $\mathbf{1 1}$ are not attacked by THF and react exclusively with EG. These reaction mechanisms and explanations result in a copolymer with a $1: 2$ composition.

When the cationic copolymerization of EG is studied, it is also possible that a chain-transfer reaction plays a role not only of the unreacted EG monomer but also by reaction of the pendant ester group of the already formed polymer. The growing oxonium ion, particularly the THF-terminated oxonium ion, is capable of reacting with the ester group to form an intermediate, as indicated in eq 7. This intermediate, especially when $\mathrm{TfO}^{-}$is the counter anion, may give ethyl triflate and a graft polymer which has developed a branching group on the carboxylic acid ester. Several of these side reactions may be the cause of the observed low molecular weight of the copolymers which were investigated in this work.

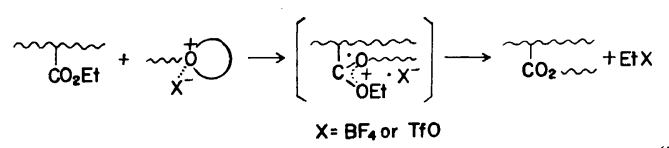

Cationic copolymerization of EG with other cyclic ethers such as ethylene oxide, 3,3-bis(chloromethyl)oxetane, oxetane, and 2-methyltetrahydrofuran were also examined. In some cases but not in all, copolymers were obtained; however, the molecular weights of these copolymers were also low (below 1500). The copolymerization effectiveness of cyclic ether comonomers as copolymerization partners for EG depends very much on the overall reactivity of the individual monomers. When the reactivity toward cationic polymerization was low, as in the cases of THF, 3,3-bis(chloromethyl)oxetane, and 2methyltetrahydrofuran, the copolymerization was very effective. When unsubstituted monomers were used, homopolymers of the more reactive monomers were obtained as a rule.

Acknowledgement. This research was a work of the Japan-U.S. Cooperative Science Program, which was supported by the Japan Society for the Promotion of Science and by the National Science Foundation of the U.S.A.

\section{REFERENCES}

1. Y. Ishii and S. Sakai in "Ring-Opening Polymerization," K. C. Frisch and S. L. Reegen Ed., Marcel Dekker, New York, N. Y., 1969.

2. J. Furukawa and T. Saegusa, "Polymerization of Aldehydes and Epoxides,"'Wiley (Interscience), New York, N. Y., 1963.

3. (a) M. E. Pruitt and J. M. Baggett, U. S. Patent, 2,706,181 (1955); (b) C. C. Price and M. Osgan, J. Am. Chem. Soc., 78, 690 (1956).

4. (a) E. J. Vandenberg, U. S. Patent 3,158,580 (1964);

(b) E. J. Vandenberg, J. Polym. Sci., 47, 486(1960); (c)

S. Ishida and S. Murahashi, J. Polym. Sci., 40, 571 (1959).

5. A. C. Farthing, Brit. Patent, 723,777 (1955).

6. E. Erlenmeyer. Jr., Jus. Liebigs. Ann. Chem., 161 (1892).

7. G. B. Payne, J. Am. Chem. Soc., 81, 4901 (1959).

8. E. G. G. Werner, Rec. Trav. Chim., 26, 442 (1949).

9. Z. Jedlinski and J. Majnusz, Makromol. Chem., 115, 111 (1972).

10. K. W. Martin and O. Vogl, U. S. Patent, 3,284,411 (1966).

11. L. Demejo, W. J. MacKnight, and O. Vogl, Polym. J., 11, 15 (1979).

12. L. Demejo, W. J. MacKnight, and O. Vogl, Polymer (London), 19, 956 (1978).

13. W. D. Emmons and A. S. Pagano, J. Am. Chem. Soc., 77, 89 (1955).

14. H. Y. Aboul-Enein, Synth. Commun., 4, 255 (1974).

15. S. Kobayashi, K. Morikawa, and T. Saegusa, Macromolecules, 8, 386 (1975).

16. (a) H. Meerwein, E. Battenberg, H. Gold, E. Pfeil, and G. Willtang, J. Prakt. Chem., 154, 83 (1939); (b) H. Meerwein, Org. Synth., 46, 113 (1966).

17. S. Kobayashi, H. Danda, and T. Saegusa, Bull. Chem. Soc. Jpn., 46, 3214 (1973).

18. M. G. Ahmed, R. W. Alder, G. H. James, M. L. Sinnott, and M. C. Whiting, J. Chem. Soc. Sect. D, 1533 (1968).

19. S. Kobayashi, K. Morikawa, and T. Saegusa, Macromolecules, 8, 952 (1975).

20. P. Kubisa and S. Penczek, J. Macromol. Sci.-Chem., A7, 1509 (1973).

21. S. Kobayashi, H. Danda, and T. Saegusa, Macromolecules, 7, 415 (1974). 